\author{
I.A.F. van der Mei \\ A.-L. Ponsonby \\ T. Dwyer \\ L. Blizzard \\ B.V. Taylor \\ T. Kilpatrick \\ H. Butzkueven \\ A.J. McMichael
}

\section{Vitamin D levels in people with multiple sclerosis and community controls in Tasmania, Australia}

Received: 22 December 2005

Received in revised form: 2 February 2006 Accepted: 11 May 2006

Published online: 11 April 2007
I.A.F. van der Mei, $\mathrm{PhD}(\square)$

Menzies Research Institute

Private Bag 23

Hobart, Tasmania 7001, Australia

Tel.: +61-3/6226 7700

Fax: +61-3/62267704

E-Mail: Ingrid.vanderMei@utas.edu.au

A.-L. Ponsonby, PhD - T. Dwyer, MD Murdoch Childrens Research Institute Melbourne, Australia

A.-L. Ponsonby, $\mathrm{PhD}$ - T. Dwyer, MD

L. Blizzard, $\mathrm{PhD}$

Menzies Research Institute

Hobart, Australia

B.V. Taylor, MD

Christchurch School of Medicine \& Health

Sciences

University of Otago

Christchurch, New Zealand

T. Kilpatrick, $\mathrm{PhD}$

H. Butzkueven, PhD

Howard Florey Institute

The University of Melbourne

Melbourne, Australia
Abstract Background Adequate $25(\mathrm{OH}) \mathrm{D}$ levels are required to prevent adverse effects on bone health. Population-based data on factors associated with $25(\mathrm{OH}) \mathrm{D}$ levels of people with MS have been lacking. Objectives To examine the prevalence and determinants of vitamin $\mathrm{D}$ insufficiency in a population-based sample of MS cases and controls, and to compare 25(OH)D status between MS cases and controls, taking into account case disability. Methods We conducted a population based case-control study in Tasmania, Australia (latitude $41-43^{\circ} \mathrm{S}$ ) on 136 prevalent cases with MS confirmed by magnetic resonance imaging and 272 community controls, matched on sex and year of birth. Measurements included serum $25(\mathrm{OH}) \mathrm{D}$, sun exposure, skin type, dietary vitamin $\mathrm{D}$ intake and disability including EDSS.

A.J. McMichael, $\mathrm{PhD}$

National Centre for Epidemiology and Population Health

The Australian National University Canberra, Australia
Results A high prevalence of vitamin $\mathrm{D}$ insufficiency was found in MS cases and controls. Among MS cases, increasing disability was strongly associated with lower levels of $25(\mathrm{OH}) \mathrm{D}$ and with reduced sun exposure. Cases with higher disability (EDSS > 3) were more likely to have vitamin D insufficiency than controls $(\mathrm{OR}=3.07(1.37,6.90)$ for $25(\mathrm{OH}) \mathrm{D} \leq 40 \mathrm{nmol} / \mathrm{l})$, but cases with low disability were not $(\mathrm{OR}=0.87(0.41,1.86))$. Conclusion The strong associations between disability, sun exposure and vitamin D status indicate that reduced exposure to the sun, related to higher disability, may contribute to the high prevalence of vitamin $\mathrm{D}$ insufficiency found in this population-based MS case sample. Active detection of vitamin $\mathrm{D}$ insufficiency among people with MS and intervention to restore vitamin $\mathrm{D}$ status to adequate levels should be considered as part of the clinical management of MS.

Key words vitamin $\mathrm{D}$. multiple sclerosis . deficiency · insufficiency · sun exposure ' disability · healthy 


\section{Introduction}

Most (90-100\%) vitamin D is produced endogenously from the action of solar radiation (particularly UVB) on precursors within sun-exposed skin [18]. Only a few foods, such as oily fish, contain significant amounts of vitamin D. Vitamin D plays an important role in maintaining bone health by preserving calcium and phosphorous homeostasis. In addition, vitamin $\mathrm{D}$ appears to play roles in immunomodulation [6], cell differentiation [40] and neural development [14]. In particular, the active form of vitamin $\mathrm{D}\left(1,25(\mathrm{OH})_{2} \mathrm{D}_{3}\right)$ can down-regulate the $\mathrm{T}$ helper type $1\left(\mathrm{Th}_{1}\right)$ cell activity through vitamin $\mathrm{D}$ receptors on activated T lymphocytes [24]. Multiple sclerosis (MS) is a disease where $\mathrm{Th}_{1}$ over-activity appears to play an important role. Serum 25 -hydroxyvitamin D $(25(\mathrm{OH}) \mathrm{D})$ is often used as a marker of vitamin D status [43], and reflects recent UVR exposure and vitamin D intake. Vitamin D deficiency is often defined as having levels below $25 \mathrm{nmol} / \mathrm{l}$, vitamin $\mathrm{D}$ insufficiency as having levels between 25 and 40 or $50 \mathrm{nmol} / \mathrm{l}$, and optimal levels as having levels above $50 \mathrm{nmol} / \mathrm{l}[31,44]$. Recent evidence suggests that the optimal serum $25(\mathrm{OH}) \mathrm{D}$ levels may be even higher, above $80 \mathrm{nmol} / \mathrm{l}$ [20].

Low vitamin $\mathrm{D}$ levels can lead to osteoporosis and osteomalacia [19] through a reduction in calcium absorption, an elevation in the blood concentration of parathyroid hormone, and an increased rate of bone resorption [15]. Serum 25(OH)D levels of at least $50 \mathrm{nmol} / \mathrm{L}$ are required for calcium homeostasis without secondary parathyroidism [19]. Low vitamin $\mathrm{D}$ levels, over time, may result in osteoporotic bone fractures [15]. Fractures might also increase through a higher risk of falls, because vitamin $D$ influences neuromuscular coordination [2]. People with MS seem to be at risk. In one study, people with MS had more fractures during adulthood (22\%) compared with controls $(2 \%)$ and lost bone mass three to six times more rapidly during two years of follow-up [9]. Apart from the substantial health care expenses, the consequences of fractures are severe, with high rates of permanent disability, particularly among elderly [26]. Prevention seems important and two metaanalyses of randomized controlled trials show that oral vitamin $\mathrm{D}$ supplementation indeed reduces the risk of fractures and falls $[3,4]$.

There are currently no population-based data on the occurrence of vitamin $D$ insufficiency and deficiency among people with MS, although vitamin D deficiency has been shown to be common among female MS patients admitted to a tertiary care hospital [29]. A small Finnish study comparing MS patients with early phase MS and hospital controls showed that MS patients had lower 25(OH)D levels than controls in summer, but similar levels in winter [38].

The possible determinants of lower serum 25(OH)D levels among people with MS have not been formally assessed. It is important to understand the reasons why people with MS may have an inadequate vitamin $\mathrm{D}$ status so that vitamin $\mathrm{D}$ deficiency and its adverse effects on bone health can be avoided. In addition, there is increasing evidence that higher sun exposure and vitamin $\mathrm{D}$ may reduce the risk of MS $[28,42]$, and some evidence to suggest that vitamin D status may influence disease course [7, 13, 17, 25, 27], but further analytical work is required to establish a causal association between vitamin D status and MS progression.

This report aims to: (i) examine the prevalence of vitamin $\mathrm{D}$ deficiency and insufficiency in a population-based sample of people with MS and age- and sex-matched community controls under the age of 60 years living in Tasmania (latitude $41-43^{\circ} \mathrm{S}$ ); (ii) describe factors associated with $25(\mathrm{OH}) \mathrm{D}$ status in MS cases and controls, and (iii) compare $25(\mathrm{OH}) \mathrm{D}$ status between MS cases and controls, taking into account case disability level.

\section{Methods}

\section{Subjects}

The source population consisted of residents under the age of 60 years living in Tasmania, Australia, with at least one grandparent who was born in Tasmania. To recruit cases, multiple population-based strategies were used including information evenings at local MS societies and letters of invitation from neurologists to patients. Eligible cases had cerebral MRI abnormalities consistent with MS [32] and clinically definite MS [33]. Of the 169 patients who responded, 30 did not meet the eligibility criteria, one refused, one deteriorated and was unable to participate and one died. Controls were selected from the roll of voters for compulsory political elections. For each case, two control subjects were randomly selected and matched to the index case on sex and birth year. For the 136 cases included in the study, estimated to comprise at least $79 \%$ of eligible cases, 272 eligible controls participated with a response rate of $76 \%$. The project received ethics approval from the Human Research Ethics Committee of the Royal Hobart Hospital.

\section{Measurements}

Disease characteristics

Each case was assessed by one of the four study neurologists; detailed disease characteristics were available for 134 of the 136 cases. These included age of first symptom, age of diagnosis, type of MS, use of immunomodulatory treatment, expanded disability status scale (EDSS) [23], Scripp's Neurologic Rating Scale [37], and MS Severity Score [34]. The MS Severity Score is based on the EDSS but takes disease duration into account [34]. The EDSS progression index was calculated by dividing the EDSS by disease duration 
since first symptom for those with a disease duration greater than 5 years $(\mathrm{n}=108)$.

\section{Serum 25(OH)D}

Serum 25(OH)D levels were measured with a commercially available radioimmunoassay (Stillwater, Minnesota-DiaSorin Inc.) for 136 cases and 262 controls.

\section{Measures related to sun exposure}

Two research assistants conducted all interviews and measurements between March 1999 and June 2001. Participants were asked, for different periods of their lives, about the amount of time they would normally have spent in the sun during weekends and holidays in winter and summer ("time in the sun" question) $(<1 \mathrm{~h}$ a day, $1-2 \mathrm{~h}$ a day, $2-3 \mathrm{~h}$ a day, $3-4 \mathrm{~h}$ a day, or $>4 \mathrm{~h}$ a day) [42], using a question validated for teenagers in this climate [10]. The weighted $\kappa$ statistic [8] (95\% confidence interval) for the "Time in the sun" question in the last three years on retest after 11 weeks for 52 cases and 52 controls was $0.68(0.48-0.87)$, and no difference in this statistic was found between cases and controls. Prior to the interview, subjects were sent a lifetime calendar and asked to fill this out for each year of their life (e.g. place of residence, school, occupation, number of days working). During the interview, subjects answered the "Time in the sun" question for summer for each year of their life and indicated, for each year of occupation, how much time (to the closest 15 minutes) they would spend outside on a working day during working hours. In this paper, sun exposure in the last year or last three years was considered to be recent sun exposure. The standardized questionnaire included a question on occupational sun exposure (mainly indoors, both indoors and outdoors, or mainly outdoors) and the frequency of the use of sunscreen (never/rarely, occasionally, most of the time, or always/ almost always). Silicon skin surface casts of the hand, measuring actinic damage, were used as an objective marker of cumulative lifetime sun exposure [42].

\section{Skin type related factors}

Skin phenotype was assessed with a spectrophotometer at the upper inner arm and buttock; body sites usually not exposed to sunlight. Cutaneous melanin density was estimated from the skin reflectance of light centered at $400 \mathrm{~nm}$ and $420 \mathrm{~nm}$ [11]. Research assistants assessed visually the skin color at the upper inner arm (fair, fair/medium, medium/olive, or olive), counted the number of nevi greater than $5 \mathrm{~mm}$ on the left arm (two or more, one, or zero), and recorded hair (red, light blonde, "mousey" blonde, light brown, dark brown, or black). The standardized questionnaire included questions on number of lifetime sunburns ( $>10$ times, 6-10 times, 2-5 times, once, or never), tendency to burn (burn then peel, burn then $\tan$, or tan only), and ability to $\tan$ (practically no $\tan$, light tan, medium tan, or dark tan).

\section{Dietary intake in the last 12 months and other factors}

Participants indicated how often on average they ate fish, eggs, and meat in the last 12 months. They were asked about their milk intake in the last 12 months $(<150 \mathrm{ml}$ per day, $150-300 \mathrm{ml}, 301-$ $600 \mathrm{ml}$, or $>600 \mathrm{ml}$ ), and whether or not they used vitamin D supplements in the last 12 months and the type of supplement. It was checked whether the supplement reported contained vitamin D. If it did not, the response was recoded as not using vitamin D supplements.

The standardized questionnaire also included questions on medical history including reported infections and immunizations, exposure to chemicals, exposure to pets and farm animals, occupation, education, smoking, alcohol intake, whether the subject was breastfed, and reproductive history for women (age of menarche, number of children and breastfeeding). For the timing of exposures, we obtained, in accordance to the recommendations of Boiko [5], either the exact age or the five-year age group at the time of the exposure.

\section{Statistical analysis}

The prevalence of vitamin D deficiency and insufficiency was calculated from the crude 25(OH)D levels and from 25(OH)D levels that had the seasonal component removed (deseasonalized). To model seasonal variation, we fitted a sinusoidal model to data on $25(\mathrm{OH}) \mathrm{D}$ levels and the month $(\mathrm{t})$ the sample was taken:

$$
25(\mathrm{OH}) \mathrm{D} \text { levels }=\beta_{0}+\beta_{1} \sin \frac{2 \pi t}{12}+\beta_{2} \cos \frac{2 \pi t}{12}
$$

The ANOVA F-test was used to decide whether there was significant seasonal variation and the amplitude was calculated using the formula $\sqrt{\beta_{1}^{2}+\beta_{2}^{2}}$. To deseasonalize the data, we subtracted the predicted value from the sinusoidal model for each subject from the actual value and added the overall mean. This was done separately for cases and controls.

To examine predictors of $25(\mathrm{OH}) \mathrm{D}$, Pearson correlation coefficients were calculated, using deseasonalized $25(\mathrm{OH}) \mathrm{D}$ values that were log-transformed to reduce skewness. The 25(OH)D values were deseasonalized to reduce the effect of the time of year that the serum sample was taken, producing $25(\mathrm{OH}) \mathrm{D}$ values that were more like those that would have obtained if all participants were measured at the same time of year. Through linear regression, tests for interaction were conducted using the coefficient and standard error of a product term. For some analyses, the case group was divided into a group with low disability (EDSS $\leq 3$ ) and a group with higher disability (EDSS $>3$ ) based on the median EDSS score of three. In the figure, EDSS scores were grouped when required to obtain mean values based on groups of more than ten subjects.

To compare cases and their matched controls, matched odds ratios and $95 \%$ confidence intervals were estimated by conditional logistic regression. The models were adjusted for the month $(t)$ that the serum sample was taken by using a seasonal term $\left(\cos \frac{2 \pi t}{12}\right)$. Tests for trend of categorical variables were undertaken by replacing the binary predictors with a single predictor taking category rank scores. A test for interaction between 25(OH)D levels and EDSS ( $>3$ vs $\leq 3$ ) was conducted using the coefficient and standard error of a product term of $25(\mathrm{OH}) \mathrm{D}$ and EDSS. Controls were given the EDSS score of their case pair. The contribution of amount of recent sun exposure to the excess of low 25(OH)D status in cases with a high EDSS score $(>3)$ compared with controls was obtained by comparing the odds ratio for low 25(OH)D status and MS before $\left(\mathrm{OR}_{\mathrm{b}}\right)$ and after $\left(\mathrm{OR}_{\mathrm{a}}\right)$ adjustment for recent sun exposure $\left(\left(\left[1-\mathrm{OR}_{\mathrm{b}}\right]-\left[1-\mathrm{OR}_{\mathrm{a}}\right]\right) /\left(1-\mathrm{OR}_{\mathrm{b}}\right)\right)[35]$. Using the lifetime calendar, average sun exposure for different age spans was calculated. For the "Time in the sun" question, categories were assigned rank scores. For occupational sun exposure, average exposure was calculated from the exact time outside during work hours and then categorized in a four level variable $(0-1 \mathrm{~h}$ a week, $1.01-2.5 \mathrm{~h}$ a week, 2.51-7 h a week, $>7 \mathrm{~h}$ a week).

\section{Results}

\section{Prevalence of vitamin D insufficiency and deficiency}

Table 1 shows the characteristics of the populationbased sample of cases with MS and community 
Table 1 Characteristics of the MS cases and controls

\begin{tabular}{lcc}
\hline & Cases & Controls \\
\hline Female/Male ratio & $92 / 44$ & $184 / 88$ \\
Mean age, years (SD) & $43.5(9.3)$ & $43.6(9.2)$ \\
Living in Tasmania in the last three years, \% (n/N) & $97.8(133 / 136)$ & $98.9(269 / 272)$ \\
Mean 25(OH)D level (SD) & $51.4(20.3)$ & $53.1(21.1)$ \\
Mean age at diagnosis, years (SD) & $34.6(9.1)$ & \\
Mean age at first symptoms, years (SD) & $31.0(9.1)$ & \\
Mean duration of MS since diagnosis, years (SD) & $9.4(7.5)$ & \\
Mean duration of MS since first symptoms, years (SD) & $12.1(8.0)$ & \\
Mean EDSS score (SD) & $3.5(2.2)$ & \\
DRB1*1501-DQB1*0602 haplotype frequency, \% (n/N) & $53.7(66 / 123)$ & \\
Type of MS & $66.4(89)$ & \\
Relapsing remitting MS, \% (n) & $26.1(35)$ & \\
Secondary progressive MS, \% (n) & $7.5(10)$ & \\
Primary progressive MS, \% (n) & & \\
\hline
\end{tabular}

controls. Table 2 shows the prevalence of vitamin $\mathrm{D}$ deficiency and insufficiency using the crude $25(\mathrm{OH}) \mathrm{D}$ levels as well as deseasonalized 25(OH)D levels, because the literature and our data suggest that the prevalence is influenced by the season in which the vitamin $\mathrm{D}$ sample was taken. Overall, the crude prevalence of vitamin D deficiency among MS cases was $11.8 \%$. After deseasonalization, the prevalence was $7.4 \%$ (Table 2). For controls, the figures were $8.8 \%$ and $6.1 \%$, respectively. The deseasonalized prevalence of vitamin D insufficiency (levels between 25 and $50 \mathrm{nmol} / \mathrm{l}$ ) among cases was $43.3 \%$, and similar for females and males. When comparing cases with controls, MS cases had a higher frequency of vitamin D levels in the range $25-40 \mathrm{nmol} / \mathrm{l}$ (Table 2).

\section{Disease characteristics and 25(OH)D status}

We examined how disease characteristics related to log-transformed 25(OH)D levels among people with MS (Table 3). EDSS (Figure 1, panel A) and Scripps neurological rating scale were most strongly associated with $25(\mathrm{OH}) \mathrm{D}$, with people with a higher disability having lower levels of 25(OH)D (Table 3). The use of immunotherapy was not associated with $25(\mathrm{OH}) \mathrm{D}$. EDSS correlated strongly with other disease characteristics (duration of MS since first symptom, $r=0.44 ;$ MS Severity Score, $r=0.83$; EDSS progression index, $r=0.58$; type of MS, $r=0.63)$ and the associations between 25(OH)D and those characteristics were reduced or disap-
Table 2 The crude and deseasonalized prevalence of vitamin $D$ deficiency and insufficiency in cases with multiple sclerosis and community controls (total sample and by gender)

\begin{tabular}{|c|c|c|c|c|c|c|c|c|c|}
\hline \multirow[b]{2}{*}{ Serum $25(\mathrm{OH}) \mathrm{D}$ level } & \multicolumn{3}{|c|}{ Total sample } & \multicolumn{3}{|c|}{ Females } & \multicolumn{3}{|c|}{ Males } \\
\hline & $\mathrm{n}$ & $\%$ & cum $\%$ & $\mathrm{n}$ & $\%$ & cum $\%$ & $\mathrm{n}$ & $\%$ & cum $\%$ \\
\hline \multicolumn{10}{|l|}{$\begin{array}{l}\text { A. Crude data } \\
\text { MS cases }\end{array}$} \\
\hline $0-25 \mathrm{nmol} / \mathrm{I}^{*}$ & 16 & 11.8 & 11.8 & 11 & 12.0 & 12.0 & 5 & 11.4 & 11.4 \\
\hline $26-40 \mathrm{nmol} / /^{* *}$ & 30 & 22.1 & 33.9 & 25 & 27.2 & 39.2 & 5 & 11.4 & 22.8 \\
\hline $41-50 \mathrm{nmol} / /^{* *}$ & 20 & 14.7 & 48.6 & 11 & 12.0 & 51.2 & 9 & 20.5 & 43.3 \\
\hline$>50 \mathrm{nmol} / \mathrm{l}$ & 70 & 51.5 & 100 & 45 & 48.9 & 100 & 25 & 56.8 & 100 \\
\hline \multicolumn{10}{|l|}{ Community controls } \\
\hline $0-25 \mathrm{nmol} / /^{*}$ & 23 & 8.8 & 8.8 & 15 & 8.6 & 8.6 & 8 & 9.1 & 9.1 \\
\hline $26-40 \mathrm{nmol} / \mathrm{I}^{* *}$ & 38 & 14.5 & 23.3 & 30 & 17.2 & 25.8 & 8 & 9.1 & 18.2 \\
\hline $41-50 \mathrm{nmol} / \mathrm{I}^{* *}$ & 66 & 25.3 & 48.6 & 44 & 25.3 & 51.1 & 22 & 25.0 & 43.2 \\
\hline$>50 \mathrm{nmol} / /$ & 135 & 51.5 & 100 & 85 & 48.9 & 100 & 50 & 56.8 & 100 \\
\hline \multicolumn{10}{|c|}{$\begin{array}{l}\text { B. Deseasonalized data } \\
\text { MS cases }\end{array}$} \\
\hline $0-25 \mathrm{nmol} / /^{*}$ & 10 & 7.4 & 7.4 & 8 & 8.7 & 8.7 & 2 & 4.5 & 4.5 \\
\hline $26-40 \mathrm{nmol} / /^{* *}$ & 35 & 25.7 & 33.1 & 26 & 28.3 & 37.0 & 9 & 20.5 & 25.0 \\
\hline $41-50 \mathrm{nmol} / /^{* *}$ & 24 & 17.6 & 50.7 & 15 & 16.3 & 53.3 & 9 & 20.5 & 45.5 \\
\hline$>50 \mathrm{nmol} / \mathrm{l}$ & 67 & 49.3 & 100 & 43 & 46.7 & 100 & 24 & 54.5 & 100 \\
\hline \multicolumn{10}{|l|}{ Community controls } \\
\hline $0-25 \mathrm{nmol} / /^{*}$ & 16 & 6.1 & 6.1 & 10 & 5.7 & 5.7 & 6 & 6.9 & 6.9 \\
\hline $26-40 \mathrm{nmol} / \mathrm{I}^{* *}$ & 50 & 19.2 & 25.3 & 39 & 22.4 & 28.1 & 11 & 12.6 & 19.5 \\
\hline $41-50 \mathrm{nmol} / /^{* *}$ & 56 & 21.5 & 46.8 & 41 & 23.6 & 51.7 & 15 & 17.2 & 36.7 \\
\hline$>50 \mathrm{nmol} / \mathrm{l}$ & 139 & 53.3 & 100 & 84 & 48.3 & 100 & 55 & 63.2 & 100 \\
\hline
\end{tabular}

*Vitamin D deficiency; ** Vitamin D insufficiency 
Table 3 Disease characteristics associated with $25(\mathrm{OH}) \mathrm{D}$ * status among MS cases

\begin{tabular}{|c|c|c|c|c|}
\hline & \multicolumn{2}{|c|}{ Unadjusted } & \multicolumn{2}{|c|}{ Adjusted for EDSS } \\
\hline & $\mathrm{r}$ & p-value & $\mathrm{r}$ & p-value \\
\hline EDSS (0-9) & -0.44 & $<0.01$ & & \\
\hline Scripps Neurological Rating Scale (15-100) & 0.45 & $<0.01$ & 0.13 & 0.15 \\
\hline Duration of MS since first symptom (1-40 yrs) & -0.27 & $<0.01$ & -0.10 & 0.28 \\
\hline Duration of MS since first symptom ( $0-5 \mathrm{yrs},>5 \mathrm{yrs})$ & -0.27 & $<0.01$ & -0.19 & 0.03 \\
\hline MS Severity Score $(0-10)$ & -0.29 & $<0.01$ & 0.16 & 0.07 \\
\hline EDSS progression index $(0-0.9)$ & -0.24 & 0.01 & -0.02 & 0.85 \\
\hline Type of MS $(1-3)^{\#}$ & -0.34 & $<0.01$ & -0.12 & 0.18 \\
\hline Immunomodulatory treatment $(0,1)^{\#}$ & 0.12 & 0.15 & 0.04 & 0.64 \\
\hline
\end{tabular}

$r=$ correlation coefficient

* The 25(OH)D levels were deseasonalized and log-transformed

\# Type of MS: 1 = relapsing remitting, 2 = secondary progressive, 3 = primary progressive; Immunomodulatory treatment: $0=$ No, $1=$ Yes peared after adjustment for EDSS (Table 3), indicating that most of the association of these variables with $25(\mathrm{OH}) \mathrm{D}$ was explained by the association of EDSS with $25(\mathrm{OH}) \mathrm{D}$. By contrast, the associations between $25(\mathrm{OH}) \mathrm{D}$ and EDSS were little changed by adjusting for the other disease characteristics (adjusted for: duration of MS since first symptom, $r=-0.38(p<0.0001)$; MS Severity Score, $r=-0.38$ $(\mathrm{p}<0.0001)$; EDSS progression index, $\mathrm{r}=-0.38$ $(\mathrm{p}<0.0001)$; type of MS, $r=-0.30(\mathrm{p}<0.0001))$. The EDSS and Scripps were closely related with a strong correlation between the two factors $(\mathrm{r}=-0.91)$, and the correlation between 25(OH)D and EDSS adjusted for Scripps $(\mathrm{r}=-0.09, \mathrm{p}=0.30)$ was similar to the correlation between $25(\mathrm{OH}) \mathrm{D}$ and Scripps adjusted for EDSS $(\mathrm{r}=0.13, \mathrm{p}=0.15)$ (Ta- ble 3). Importantly, higher disability, measured by a higher EDSS or lower Scripps score, were also strongly associated with lower levels of recent sun exposure (EDSS: $\mathrm{r}=-0.39, \mathrm{p}<0.0001$ (Figure 1, panel B); Scripps: $\mathrm{r}=0.37, \mathrm{p}<0.0001)$.

\section{Seasonal variation}

To explore the seasonal variation in the levels of $25(\mathrm{OH}) \mathrm{D}$, we fitted a sinusoidal model to $25(\mathrm{OH}) \mathrm{D}$ levels and the month the serum sample was taken. We observed a significant seasonal pattern $(\mathrm{p}<0.001)$ among cases. The maximum fitted value $(63.7 \mathrm{nmol} / \mathrm{l})$ was reached in late February, and the minimum fitted value $(36.2 \mathrm{nmol} / \mathrm{l})$ was reached in
Fig. 1 Higher disability, measured by EDSS score, among people with MS is associated with lower serum $25(\mathrm{OH}) \mathrm{D}$ levels (Panel A), and reduced summer sun exposure in the last year on leisure days (Panel B)
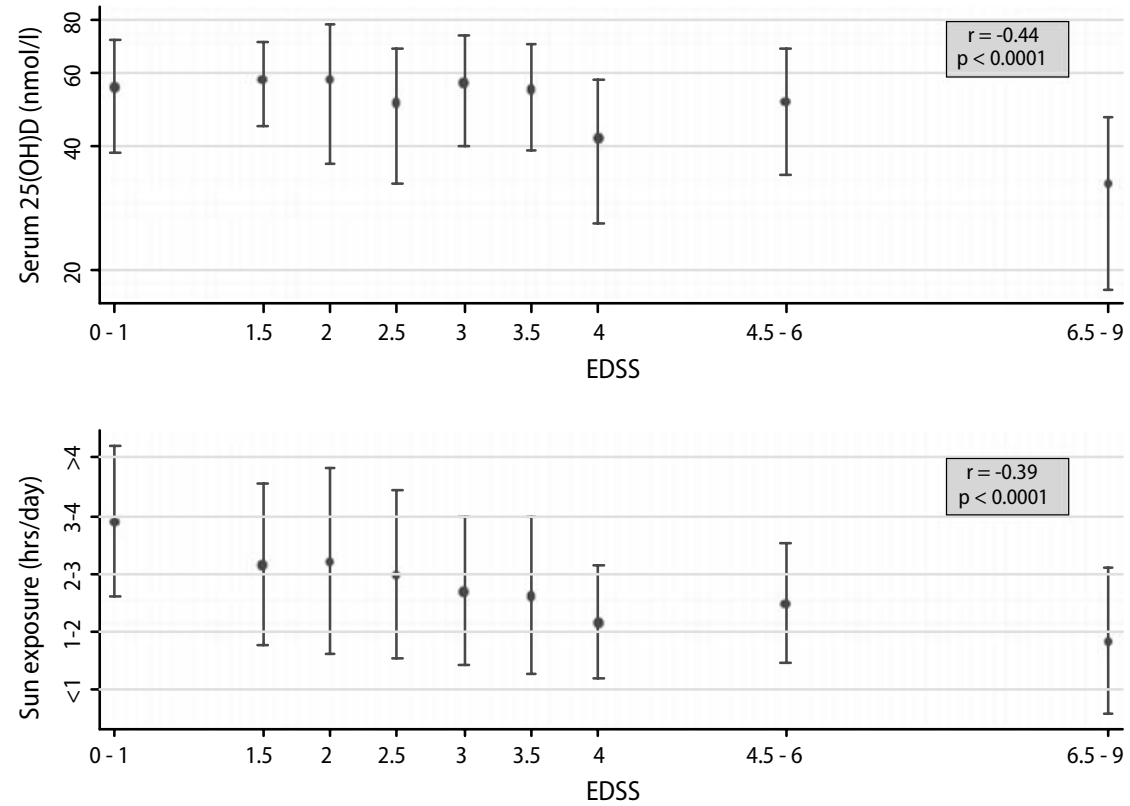
Table 4 Factors associated with 25(OH)D status* among MS cases and controls

\begin{tabular}{|c|c|c|c|}
\hline \multirow[b]{3}{*}{ Factor } & \multicolumn{2}{|c|}{ Correlation coefficient ( $p$-value) } & \multirow{3}{*}{$\begin{array}{l}\text { Controls } \\
n=262\end{array}$} \\
\hline & \multicolumn{2}{|l|}{ MS cases } & \\
\hline & High $\operatorname{EDSS}(>3) n=56$ & Low $\operatorname{EDSS}(\leq 3) n=78$ & \\
\hline Age (years) & $-0.34(0.01)$ & $-0.07(0.54)$ & $-0.06(0.37)$ \\
\hline Female & $-0.22(0.10)$ & $-0.07(0.54)$ & $-0.06(0.32)$ \\
\hline \multicolumn{4}{|l|}{ Measures related to recent sun exposure } \\
\hline Time in the sun in summer on leisure days in the last 3 years ( 5 levels) & $0.39(<0.01)$ & $0.07(0.51)$ & $0.16(0.01)$ \\
\hline Time in the sun in winter on leisure days in the last 3 years ( 5 levels) & $0.35(<0.01)$ & $0.07(0.51)$ & $0.14(0.03)$ \\
\hline Time in the sun in summer/winter on leisure days in the last 3 years** (5 levels) & $0.39(<0.01)$ & $0.19(0.09)$ & $0.15(0.02)$ \\
\hline Time in the sun in summer on leisure days in the last year (C) (5 levels) & $0.40(<0.01)$ & $0.12(0.28)$ & $0.23(<0.01)$ \\
\hline Time in the sun in summer during work hours in the last year $(C)^{* * *}$ (4 levels) & $-0.05(0.84)$ & $0.17(0.25)$ & $0.08(0.27)$ \\
\hline Use of sunscreen in the last 3 years (4 levels) & $0.01(0.96)$ & $-0.15(0.20)$ & $-0.03(0.59)$ \\
\hline \multicolumn{4}{|l|}{ Measures related to past sun exposure } \\
\hline Average time in the sun in summer on leisure days at age $6-15$ yrs ( 5 levels) & $0.23(0.09)$ & $-0.02(0.86)$ & $0.09(0.15)$ \\
\hline Average time in the sun in summer on leisure days prior to disease onset ${ }^{\#}$ ( 5 levels) & $-0.07(0.60)$ & $0.26(0.03)$ & $0.04(0.56)$ \\
\hline Job for the longest period of life (3 levels) & $0.11(0.44)$ & $0.18(0.11)$ & $0.09(0.14)$ \\
\hline Marked actinic damage (grade 3 to 6 ) & $0.03(0.95)$ & $-0.04(0.76)$ & $0.11(0.11)$ \\
\hline \multicolumn{4}{|l|}{ Skin type related factors (from light to darker complexion) } \\
\hline Skin melanin density at upper inner arm, \% & $0.40(<0.01)$ & $0.28(0.01)$ & $0.16(0.01)$ \\
\hline Skin melanin density at buttock, $\%$ & $0.19(0.24)$ & $0.23(0.05)$ & $0.10(0.15)$ \\
\hline Skin color by nurse observation (4 levels) & $0.11(0.42)$ & $0.21(0.06)$ & $0.14(0.02)$ \\
\hline Ability to tan (4 levels) & $0.09(0.51)$ & $0.24(0.03)$ & $0.14(0.02)$ \\
\hline Tendency to burn (3 levels) & $0.15(0.27)$ & $0.02(0.86)$ & $0.06(0.35)$ \\
\hline Hair color (6 levels) & $0.07(0.60)$ & $-0.04(0.65)$ & $-0.07(0.25)$ \\
\hline Lifetime severe sunburns ( 5 levels) & $-0.06(0.63)$ & $0.01(0.90)$ & $-0.03(0.59)$ \\
\hline Number of naevi $>5 \mathrm{~mm}$ on left arm (3 levels) & $-0.17(0.24)$ & $0.03(0.78)$ & $0.05(0.38)$ \\
\hline \multicolumn{4}{|l|}{ Dietary intake in the last 12 months } \\
\hline Vitamin D supplementation (No/Yes) & $-0.03(0.84)$ & $0.08(0.48)$ & $-0.02(0.74)$ \\
\hline Fish consumption (times per month) & $0.22(0.10)$ & $0.13(0.24)$ & $0.05(0.42)$ \\
\hline Milk consumption (4 levels) ${ }^{\# \#}$ & $-0.11(0.42)$ & $-0.01(0.96)$ & $-0.05(0.41)$ \\
\hline Egg consumption (eggs per month) & $-0.06(0.66)$ & $0.11(0.32)$ & $-0.004(0.95)$ \\
\hline Meat consumption (times per month) & $-0.01(0.92)$ & $-0.04(0.76)$ & $0.09(0.16)$ \\
\hline
\end{tabular}

* The 25(OH)D levels were deseasonalized and log-transformed

** For subjects who had their serum sample taken in the summer and autumn months, sun exposure in summer was used and for subjects who had their serum sample taken in the winter and spring months, sun exposure in winter was used. ${ }^{* * *}$ Among those who worked (cases high EDSS $n=18$, cases low EDSS $n=46$, controls $n=185$ )

\# For controls, the age of onset was used of the case that they were matched to." None of the common milk brands in Tasmania are fortified with vitamin D. (C) Measure obtained from the lifetime calendar

late August. The amplitude of this fitted model, half this range, was $13.7 \mathrm{nmol} / \mathrm{l}$. When we compared the seasonality among cases with a higher EDSS score $(>3)$ with those with a low EDSS score, we noticed a weaker seasonality among those with a higher EDSS score (amplitude 10.3, $\mathrm{p}=0.04$, vs amplitude 18.2, $\mathrm{p}<0.001$ for low EDSS, test for interaction $\mathrm{p}=0.15)$. This finding seems to be in line with a more constant sun exposure behavior among cases with a high EDSS score. Among cases with a higher EDSS score, $73.2 \%$ reported a similar amount of sun in summer and winter, while $21.4 \%$ reported more sun in summer and $5.4 \%$ more sun in winter. Among cases with a low EDSS score, only $46.2 \%$ reported a similar amount of sun in summer and winter, while $35.9 \%$ reported more in summer and $17.9 \%$ more in winter. The patterns for controls were similar to that of the cases with a low EDSS (data not shown).

\section{Factors associated with 25(OH)D status among cases with MS and controls}

We next examined which factors were associated with log-transformed 25(OH)D levels among cases with a higher EDSS score, cases with a low EDSS score, and controls (Table 4). Recent sun exposure during leisure time was strongly associated with vitamin D status among cases with a higher EDSS score, and moderately associated among controls. For cases with a low EDSS score, there was only a moderate association with recent sun exposure during leisure time when we aligned the season that the vitamin D sample was taken with the appropriate sun exposure question (summer or winter). Differences in effect for males and females might partly explain the weaker associations between recent sun exposure and vitamin D status among cases with a low EDSS score. We found a strong positive correlation between vitamin $\mathrm{D}$ status 
and recent sun exposure during leisure time for females with a low EDSS score $(r=0.26, p=0.05)$, while no association was found for males with a low EDSS score $(r=0.01, p=98$, test for interaction $\mathrm{p}=0.35)$. For males with a low EDSS score, sun exposure during work seemed much more important (males: $\mathrm{r}=0.62, \mathrm{p}=0.03$; females: $\mathrm{r}=-0.03$, $\mathrm{p}=0.87$, test for interaction $\mathrm{p}=0.03$ ). In all groups, melanin density (at the upper inner arm and buttock) or darker skin color was positively associated with 25(OH)D (Table 4), and these associations persisted after adjustment for recent sun exposure and use of sunscreen/clothing. In this sample, a weak non-significant association was observed between sun exposure and melanin or skin type for cases $(r=0.11$, $\mathrm{p}=0.21$ for melanin at upper inner arm), and no association for controls $(r=0.01, p=0.87)$. Age was negatively associated with $25(\mathrm{OH}) \mathrm{D}$ among cases with a higher EDSS, but not among cases with a low EDSS or controls. Part of the association was explained by EDSS ( $\mathrm{r}=-0.25, \mathrm{p}=0.06$ after adjustment for EDSS). Vitamin D supplementation was used by $15.4 \%$ (12/ 78 ) of cases with a low EDSS, $7.1 \%(4 / 56)$ of cases with a higher EDSS and 8.1\% (22/272) of the controls and was not found to be associated with $25(\mathrm{OH}) \mathrm{D}$. Fish consumption was associated, although not significantly, with $25(\mathrm{OH}) \mathrm{D}$ status among people with a higher EDSS, but not among those with a low EDSS or controls. The following factors, examined but not reported in Table 4, did not relate to $25(\mathrm{OH}) \mathrm{D}$ status: - season of birth (Jan-March, April-June, July-Sept, Oct-Dec), history of being breastfed as an infant, consumption of fish, milk, eggs or vitamin D supplements at age 10-15 years, level of education, and whether or not subjects currently smoked tobacco. The main factors associated with $25(\mathrm{OH}) \mathrm{D}$ were not dependent on the method of using deseasonalized
$25(\mathrm{OH}) \mathrm{D}$ values. For example, the correlations between non-deseasonalized $25(\mathrm{OH}) \mathrm{D}$ and recent time in the sun in summer was $0.31(p=0.02)$ for cases with a high disability and $0.22(\mathrm{p}<0.01)$ for controls, and the correlations between non-deseasonalized $25(\mathrm{OH}) \mathrm{D}$ and melanin density at the upper inner arm was $0.39(\mathrm{p}<0.01)$ for cases with a high disability and $0.24(\mathrm{p}<0.01)$ for controls.

\section{Comparison of vitamin D status in MS cases and age- and sex-matched controls}

Compared with those with 25(OH)D levels $>40 \mathrm{nmol} / \mathrm{l}$, having lower levels of $25(\mathrm{OH}) \mathrm{D}$ was moderately associated with MS (OR $1.62(0.96,2.74)$ after adjustment for the month the serum sample was taken). When we stratified by EDSS score, we observed a strong positive association among MS cases (and their matched controls) with a higher EDSS, while no or at best a weak negative association among those with a low EDSS (test for interaction, $\mathrm{p}=0.04$ ) (Table 5). Thus, the risk of becoming more vitamin $\mathrm{D}$ insufficient or deficient than controls seems to occur among people with MS that have a higher disability.

After adjustment for amount of recent sun exposure in cases with a higher EDSS compared with their matched controls, the odds ratio for low $25(\mathrm{OH}) \mathrm{D}$ decreased from $3.07(1.37,6.90)$ to $2.44(0.98,6.04)$, and an additional adjustment for winter sun exposure in the last 3 years reduced the odds ratio to $2.13(0.84$, $5.37)$. This indicates that a material part $(45 \%)$ of the association between low 25(OH)D status and MS appears to be due to the fact that cases with a higher disability had had less recent sun exposure. Additional adjustments for the use of sunscreen, melanin density at the upper inner arm and fish intake did not change the association (odds ratio $2.13(0.54,8.46)$ ).

Table 5 The distribution of serum 25(OH)D for MS cases and controls with associated odds ratios and $95 \%$ confidence intervals by EDSS score

\begin{tabular}{|c|c|c|c|c|c|c|c|c|c|c|}
\hline \multirow{3}{*}{$\begin{array}{l}\text { Serum 25(OH)D level } \\
>60 \mathrm{nmol} / \mathrm{l}\end{array}$} & \multicolumn{5}{|c|}{ Case EDSS score $>3$} & \multicolumn{5}{|c|}{ Case EDSS score $\leq 3$} \\
\hline & \multicolumn{2}{|c|}{$\begin{array}{l}\text { Cases } \\
\mathrm{n}(\%)\end{array}$} & \multicolumn{2}{|c|}{$\begin{array}{l}\text { Controls } \\
\mathrm{n}(\%)\end{array}$} & \multirow{2}{*}{$\begin{array}{l}\text { Adjusted Odds ratio* }(95 \% \mathrm{Cl}) \\
1\end{array}$} & \multicolumn{2}{|c|}{$\begin{array}{l}\text { Cases } \\
\mathrm{n}(\%)\end{array}$} & \multicolumn{2}{|c|}{$\begin{array}{l}\text { Controls } \\
\text { n (\%) }\end{array}$} & \multirow{2}{*}{$\frac{\text { Adjusted Odds Ratio* (95\% Cl) }}{1}$} \\
\hline & 11 & (19.6) & 28 & (25.7) & & 27 & (34.6) & 50 & (33.6) & \\
\hline $51-60 \mathrm{nmol} / \mathrm{l}$ & 9 & (16.1) & 25 & (22.9) & $0.85(0.26,2.73)$ & 23 & (29.5) & 31 & (20.8) & $1.36(0.64,2.92)$ \\
\hline $41-50 \mathrm{nmol} / \mathrm{l}$ & 12 & (21.4) & 32 & (29.4) & $0.93(0.36,2.43)$ & 7 & $(9.0)$ & 33 & (22.1) & $0.40(0.16,1.04)$ \\
\hline $26-40 \mathrm{nmol} / \mathrm{l}$ & 15 & (26.8) & 14 & (12.8) & $2.86(0.90,9.15)$ & 15 & (19.2) & 23 & (15.4) & $1.13(0.45,2.85)$ \\
\hline $\begin{array}{l}0-25 \mathrm{nmol} / \mathrm{l} \\
\text { Linear trend }\end{array}$ & 9 & (16.1) & 10 & $(9.2)$ & $\begin{array}{l}2.89(0.79,10.58) \\
p=0.04\end{array}$ & 6 & (7.7) & 12 & (8.1) & $\begin{array}{l}0.80(0.27,2.65) \\
p=0.45\end{array}$ \\
\hline Test for interaction with EDSS & & & & & & $p=$ & & & & \\
\hline $\begin{array}{l}\text { Dichotomized } \\
>40 \mathrm{nmol} / \mathrm{l}\end{array}$ & 32 & (57.1) & 85 & (78.0) & 1 & 57 & (73.1) & 114 & (76.5) & 1 \\
\hline $\begin{array}{l}\leq 40.00 \mathrm{nmol} / \mathrm{l} \\
\text { Test for interaction with EDSS }\end{array}$ & 24 & (42.9) & 24 & (22.0) & $3.07(1.34,7.01)$ & $\begin{array}{l}21 \\
p=\end{array}$ & $7^{(26.9)}$ & 35 & (23.5) & $1.12(0.55,2.29)$ \\
\hline
\end{tabular}

* Matched odds ratios adjusted for the month the serum sample was taken using a seasonal term 


\section{Discussion}

In this population-based sample of people with MS under the age of 60 years living at latitudes $41-43^{\circ} \mathrm{S}$, more than half had vitamin D insufficiency (serum 25(OH)D: $50.7 \% \leq 50 \mathrm{nmol} / \mathrm{l})$. Increasing disability was strongly associated with lower levels of $25(\mathrm{OH}) \mathrm{D}$ and with lower levels of sun exposure. People with a higher disability also had more often low levels of vitamin $\mathrm{D}(\leq 40 \mathrm{nmol} / \mathrm{l})$ compared with their age and sex matched controls, while people with a low disability had similar levels of vitamin D compared with controls. Nearly half of the excess risk of low vitamin D among people with a higher disability compared with controls was statistically attributable to the lower sun exposure.

One of the strengths of this study is that it is a population-based sample rather than a hospital sample, where patients generally tend to have a higher disability and longer disease duration. It is conceivable that we have missed some people with a high disability, although many would have been older than 60 years and would therefore fall outside the study source population. Even though the reliability of selfreported sun exposure was similar for cases and controls, the measures of self-reported sun exposure are likely to have more random misclassification than does serum 25(OH)D. Therefore, the potential contribution of recent sun exposure to the excess of low 25(OH)D status among disabled cases may even be higher than estimated in this study. This study could not examine vitamin D status as a causal factor of MS, because prevalent, not incident, cases were studied, and disease related changes in outdoor behavior would have influenced vitamin $\mathrm{D}$ status.

We found a high prevalence of vitamin D insufficiency in this population-based sample with MS, particularly among those with a higher disability. This is in line with the higher prevalence of vitamin $\mathrm{D}$ insufficiency that was found among (more disabled) women with MS recruited from a tertiary care hospital in New York (latitude $\left.40^{\circ} \mathrm{N}\right)(69 \%<50 \mathrm{nmol} / \mathrm{l}$, mean EDSS score 6.9) [29]. Our study, indeed, indicates that disability was strongly associated with $25(\mathrm{OH}) \mathrm{D}$ levels. In addition, disability was strongly associated with reduced sun exposure, and sun exposure levels explained nearly half of the excess risk of low vitamin $\mathrm{D}$ found among cases with a higher disability compared with age- and sex-matched controls. Thus, increasing disability may reduce outdoor behavior and sun exposure and, in turn, increase the risk of vitamin $\mathrm{D}$ insufficiency. Prospective studies are required to examine whether low vitamin D among higher disability cases reflects not only disease related changes in outdoor behavior (influencing vitamin D status) but also a direct effect of low vitamin $\mathrm{D}$ on disability.
Age and sex matched community controls also had a concerning high prevalence of vitamin D insufficiency $(46.8 \% \leq 50 \mathrm{nmol} / \mathrm{l})$ with more than half of those with insufficiency having levels $\leq 40 \mathrm{nmol} / \mathrm{l}$. Again, recent sun exposure was a strongly associated with serum $25(\mathrm{OH}) \mathrm{D}$.

The findings of a large environmental influence (sun exposure) on case vitamin D status and similar (albeit low) levels of vitamin D among low disability cases and controls indicates that people with MS are unlikely to have a low $25(\mathrm{OH}) \mathrm{D}$ status that is predominantly genetically determined or is the result of having had the initial MS onset. However, the bioavailability of the active hormone, $1,25(\mathrm{OH}) 2 \mathrm{D} 3$, will still depend on constitutional differences such as allelic variation in the vitamin $\mathrm{D}$ receptor (VDR) gene. Allelic VDR status has been associated with MS in a Japanese $[16,30]$ but not in a Canadian population [39]. Here, in this Caucasian population, cases and controls more often had low vitamin D when they had a fairer skin type. This finding is, however, in contrast with the observation that fairer-skinned people absorb more UVR for a given level of ambient UVR compared with darker-skinned people [21], leaving them less prone to vitamin D deficiency [18]. While fairer-skinned people tend to avoid the sun compared with darker-skinned people [12], this association was not observed in our sample. As a result, the associations between vitamin $\mathrm{D}$ and skin type did not reduce after adjustment for sun exposure and use of sunscreen and clothing. Also, sun avoidance behavior is difficult to measure precisely and we can not rule out residual confounding.

We also observed that there is less seasonal variation among those with a higher disability, likely to be the result of a more constant sun exposure behavior. This is in agreement with Nieves et al. who found no seasonality in serum $25(\mathrm{OH}) \mathrm{D}$ in their sample of women with a relatively high level of disability [29]. People with a higher disability might not increase their sun exposure in summer as the heat of the sun may exacerbate their symptoms. Heat intolerance is a well-recognized feature of MS, which could lead to an avoidance of the sun. In a recent survey, the high correlation between people with MS reporting that high temperatures made their MS worse and that sun exposure made their MS worse may be related to solar heat [36]. Again, prospective data are required to unravel the nature of the association between sun exposure and heat intolerance. A study on fatigue showed that people with a higher disability are more often fatigued, and that heat makes the symptoms of fatigue worse, which occurred more often in those with more severe fatigue [1]. Thus, in people with MS, solar light is likely to be of clinical benefit, while solar heat may have adverse effects on MS symptoms. 
In general, most vitamin $\mathrm{D}$ is produced through exposure to UVR, while the contribution of dietary vitamin $\mathrm{D}$ is low [18]. This might be the reason why vitamin $\mathrm{D}$ supplements or foods containing vitamin $\mathrm{D}$ did not predict 25(OH)D levels in controls and cases with a low disability. In cases with a higher disability, where $25(\mathrm{OH}) \mathrm{D}$ status and sun exposure levels were particularly low, we did find a positive association between fish intake and serum 25(OH)D. Additional reasons for not finding an association between vitamin supplementation and serum $25(\mathrm{OH}) \mathrm{D}$ status could include measurement error, insufficient use or dosage to produce a substantial effect, and the use of vitamin $\mathrm{D}_{2}$ in Australia which seems not as effective as vitamin $\mathrm{D}_{3}$ [41]. The low influence of vitamin $\mathrm{D}$ supplementation on $25(\mathrm{OH}) \mathrm{D}$ status highlights previous recommendations [19] that clinicians should not merely recommend vitamin $\mathrm{D}$ supplementation, but rather should monitor and treat vitamin $\mathrm{D}$ insufficiency until adequate vitamin $\mathrm{D}$ levels are achieved. Therapeutic options which increase the amount of exposure to UVR while avoiding adverse heat-related effects should be considered as well as oral vitamin $\mathrm{D}$ supplementation.

There is substantial evidence that vitamin D insufficiency increases the risk of falls and fractures $[3,15]$. This seems to apply to MS, as a lower bone mass and an increased number of fractures has been observed in MS patients compared with age- and sexmatched controls [9, 29]. Therefore, preventing vitamin D insufficiency among people with MS is warranted, even if the possible adverse effects of vitamin D insufficiency on MS progression are not conclusive. Here, the cross-sectional design was not appropriate to examine MS progression. A longitudinal study with serial vitamin $\mathrm{D}$ and progression measurements or a randomized clinical trial would be the preferred epidemiological designs to answer whether sun exposure or vitamin D status might influence MS progression. In a recent paper, vitamin D status has also been found to be associated with neuropsychological function [22].

In conclusion, a high prevalence of vitamin $\mathrm{D}$ insufficiency was found in this population-based sample of people with MS. People with a higher disability seemed especially prone to insufficient levels of vitamin $D$, probably as a result of low levels sun exposure. Active detection of vitamin D insufficiency among people with MS and intervention to restore vitamin D status to adequate levels should be considered as part of the clinical management of MS.

\begin{abstract}
Acknowledgements We thank the participants and Trish Groom and Jane Pittaway for conducting the interviews, Natasha Newton for administrative support and data entry, Sue Sawbridge and Tim Albion for the development and management of the database, the Tasmanian Multiple Sclerosis Society for assisting with the recruitment of volunteers, and $\mathrm{H}$ Butkueven, A Hughes, B Drulovis, and S Sjieka who were involved with the clinical diagnosis. This project was supported with funding from the National Health and Medical Research Council of Australia, the Australian Rotary Health Research Fund, and MS Australia. IvdM was supported by the Cooperative Research Centre for Discovery of Genes for Common Human Diseases (gene-CRC), and TJK was a Viertel fellow.
\end{abstract}

\section{References}

1. Bergamaschi R, Romani A, Versino M, Poli R, Cosi V (1997) Clinical aspects of fatigue in multiple sclerosis. Funct Neurol 12:247-251

2. Bischoff HA, Stahelin HB, Dick W, Akos R, Knecht M, Salis C, Nebiker M, Theiler R, Pfeifer M, Begerow B, Lew RA, Conzelmann M (2003) Effects of vitamin $\mathrm{D}$ and calcium supplementation on falls: a randomized controlled trial. J Bone Miner Res 18:343-351

3. Bischoff-Ferrari HA, Dawson-Hughes B, Willett WC, Staehelin HB, Bazemore MG, Zee RY, Wong JB (2004) Effect of Vitamin D on falls: a meta-analysis. JAMA 291:1999-2006

4. Bischoff-Ferrari HA, Willett WC, Wong JB, Giovannucci E, Dietrich T, DawsonHughes B (2005) Fracture prevention with vitamin $D$ supplementation: a meta-analysis of randomized controlled trials. JAMA 293:2257-2264
5. Boiko A (1997) Data collection guidelines for questionnaires to be used in case-control studies of multiple sclerosis. Neurology 49:S75-80

6. Bouillon R, Okamura WH, Norman AW (1995) Structure-Function Relationships in the Vitamin D Endocrine System. Endocrine Rev 16:200-257

7. Cantorna MT, Hayes CE, DeLuca HF (1996) 1,25-Dihydroxyvitamin D3 reversibly blocks the progression of relapsing encephalomyelitis, a model of multiple sclerosis. Proc Natl Acad Sci U S A 93:7861-7864

8. Cohen JA (1968) nominal scale agreement with provision for scaled disagreement or partial credit. Am Psychol Assoc 70:213-219

9. Cosman F, Nieves J, Komar L, Ferrer G Herbert J, Formica C, Shen V, Lindsay R (1998) Fracture history and bone loss in patients with MS. Neurology 51:1161-1165
10. Dwyer T, Blizzard L, Gies PH, Ashbolt R, Roy C (1996) Assessment of habitual sun exposure in adolescents via questionnaire-a comparison with objective measurement using polysulphone badges. Melanoma Res 6:231-239

11. Dwyer T, Muller HK, Blizzard L, Ashbolt R, Phillips G (1998) The use of spectrophotometry to estimate melanin density in Caucasians. Cancer Epidemiol Biomarkers Prev 7:203-206

12. Dwyer T, Prota G, Blizzard L, Ashbolt R, Vincensi MR (2000) Melanin density and melanin type predict melanocytic naevi in 19-20 year olds of northern European ancestry. Melanoma Res 10:387-394

13. Embry AF, Snowdon LR, Vieth $R$ (2000) Vitamin D and seasonal fluctuations of gadolinium-enhancing magnetic resonance imaging lesions in multiple sclerosis. Ann Neurol 48:271272 
14. Eyles DW, Brown J, Mackay-Sim A, McGrath J, Feron F (2002) Vitamin $\mathrm{D}_{3}$ and brain development. Neuroscience. 1-44

15. Feskanich D, Willett WC, Colditz GA (2003) Calcium, vitamin D, milk consumption, and hip fractures: a prospective study among postmenopausal women. Am J Clin Nutr 77:504-511

16. Fukazawa T, Yabe I, Kikuchi S, Sasaki H, Hamada T, Miyasaka K, et al. (1999) Association of vitamin $\mathrm{D}$ receptor gene polymorphism with multiple sclerosis in Japanese. J Neurol Sci 166:47-52

17. Goldberg P, Fleming MC, Picard EH (1986) Multiple sclerosis: decreased relapse rate through dietary supplementation with calcium, magnesium and vitamin D. Med Hypotheses 21:193-200

18. Holick MF (1994) McCollum Award Lecture, 1994: vitamin D-new horizons for the 21st century. Am J Clin Nutr 60:619-630

19. Holick MF (2004) Vitamin D: importance in the prevention of cancers, type 1 diabetes, heart disease, and osteoporosis. Am J Clin Nutr 79:362-371

20. Hollis BW (2005) Circulating 25-hydroxyvitamin D levels indicative of vitamin $\mathrm{D}$ sufficiency: implications for establishing a new effective dietary intake recommendation for vitamin $\mathrm{D}$. J Nutr 135:317-322

21. Jablonski NG, Chaplin G (2000) The evolution of human skin coloration. J Hum Evol 39:57-106

22. Jorde R, Waterloo K, Saleh F, Haug E, Svartberg J (2005) Neuropsychological function in relation to serum parathyroid hormone and serum 25-hydroxyvitamin D levels The Tromso study. J Neurol

23. Kurtzke JF (1983) Rating neurologic impairment in multiple sclerosis: an expanded disability status scale (EDSS). Neurology 33:1444-1452

24. Lemire JM (1992) Immunomodulatory Role of 1,25-Dihydroxyvitamin $\mathrm{D}_{3}$. Journal of Cellular Biochemistry 49:2631

25. Lemire JM, Archer DC (1991) 1,25-dihydroxyvitamin D3 prevents the in vivo induction of murine experimental autoimmune encephalomyelitis. J Clin Invest 87:1103-1107
26. Magaziner J, Hawkes W, Hebel JR, Zimmerman SI, Fox KM, Dolan M, Felsenthal G, Kenzora J (2000) Recovery from hip fracture in eight areas of function. J Gerontol A Biol Sci Med Sci 55:M498-507

27. Mahon BD, Gordon SA, Cruz J, Cosman F, Cantorna MT (2003) Cytokine profile in patients with multiple sclerosis following vitamin $\mathrm{D}$ supplementation. J Neuroimmunol 134:128-132

28. Munger KL, Zhang SM, O'Reilly E, Hernan MA, Olek MJ, Willett WC, Ascherio A (2004) Vitamin D intake and incidence of multiple sclerosis. Neurology 62:60-65

29. Nieves J, Cosman F, Herbert J, Shen V, Lindsay R (1994) High prevalence of vitamin $\mathrm{D}$ deficiency and reduced bone mass in multiple sclerosis. Neurology 44:1687-1692

30. Niino M, Fukazawa T, Yabe I, Kikuchi S, Sasaki H, Tashiro K (2000) Vitamin $\mathrm{D}$ receptor gene polymorphism in multiple sclerosis and the association with HLA class II alleles. J Neurol Sci 177:65-71

31. Nowson CA, Margerison C (2002) Vitamin D intake and vitamin D status of Australians. Med J Aust 177:149-152

32. Paty DW, Oger JJ, Kastrukoff LF, Hashimoto SA, Hooge JP, Eisen AA, Eisen KA, Purves SJ, Low MD, Brandejs V et al. (1988) MRI in the diagnosis of MS: a prospective study with comparison of clinical evaluation, evoked potentials, oligoclonal banding, and CT. Neurology 38:180-185

33. Poser CM, Paty DW, Scheinberg L, McDonald WI, Davis FA, Ebers GC Johnson KP, Sibley WA, Silberberg DH, Tourtellotte WW (1983) New diagnostic criteria for multiple sclerosis: guidelines for research protocols. Ann Neurol 13:227-231

34. Roxburgh RH, Seaman SR, Masterman T, Hensiek AE, Sawcer SJ, Vukusic S, Achiti I, Confavreux C, Coustans M, le Page E, Edan G, McDonnell GV, Hawkins S, Trojano $M$, Liguori $M$, Cocco $E$, Marrosu MG, Tesser F, Leone MA, Weber A, Zipp F, Miterski B, Epplen JT, Oturai A, Sorensen PS, Celius EG, Lara NT, Montalban X, Villoslada P, Silva AM, Marta M, Leite I, Dubois B, Rubio J, Butzkueven H, Kilpatrick T,
Mycko MP, Selmaj KW, Rio ME, Sa M, Salemi G, Savettieri G, Hillert J, Compston DA (2005) Multiple Sclerosis Severity Score: using disability and disease duration to rate disease severity. Neurology 64:1144-1151

35. Salonen JT, Tuomilehto J, Nissinen A, Kaplan GA, Puska P (1989) Contribution of risk factor changes to the decline in coronary incidence during the North Karelia project: a within-community analysis. Int J Epidemiol 18:595-601

36. Simmons RD, Ponsonby AL, van der Mei IA, Sheridan P (2004) What affects your MS? Responses to an anonymous, Internet-based epidemiological survey. Mult Scler 10:202-211

37. Sipe JC, Knobler RL, Braheny SL, Rice GP, Panitch HS, Oldstone MB (1984) A neurologic rating scale (NRS) for use in multiple sclerosis. Neurology 34:13681372

38. Soilu-Hanninen M, Airas L, Mononen I, Heikkila A, Viljanen M, Hanninen A (2005) 25-Hydroxyvitamin D levels in serum at the onset of multiple sclerosis. Mult Scler 11:266-271

39. Steckley JL, Dyment DA, Sadovnick AD, Risch N, Hayes C, Ebers GC (2000) Genetic analysis of vitamin D related genes in Canadian multiple sclerosis patients. Canadian Collaborative Study Group. Neurology 54:729-732

40. Studzinski GP, Moore DC (1995) Sunlight-can it prevent as well as cause cancer? Cancer Res 55:4014-4022

41. Trang HM, Cole DE, Rubin LA, Pierratos A, Siu S, Vieth R (1998) Evidence that vitamin D3 increases serum 25hydroxyvitamin D more efficiently than does vitamin D2. Am J Clin Nutr 68:854-858

42. van der Mei IA, Ponsonby AL, Dwyer T, Blizzard L, Simmons R, Taylor BV, Butzkueven H, Kilpatrick T (2003) Past exposure to sun, skin phenotype, and risk of multiple sclerosis: case-control study. BMJ 327:316

43. Vieth R (1999) Vitamin D supplementation, 25-hydroxyvitamin D concentrations, and safety. Am J Clin Nutr 69:842-856

44. Vieth R, Chan PC, MacFarlane GD (2001) Efficacy and safety of vitamin D3 intake exceeding the lowest observed adverse effect level. Am J Clin Nutr 73:288-294 